\title{
Nursing and medical contribution to Defence Healthcare Engagement: initial experiences of the UK Defence Medical Services
}

\author{
Douglas M Bowley, ${ }^{1}$ D Lamb, ${ }^{2}$ P Rumbold, ${ }^{3}$ P Hunt, ${ }^{4}$ J Kayani, ${ }^{5}$ A M Sukhera ${ }^{6}$
}

\begin{abstract}
${ }^{1}$ Department of Surgery, 16 Medical Regiment, Merville Barracks, Colchester, UK ${ }^{2}$ RCDM (Research and Academia), ICT Centre Birmingham Research Park, Birmingham, UK

${ }^{3}$ Queen Alexandra's Royal Naval Nursing Service, Birmingham, UK

${ }^{4}$ Emergency Department, James Cook University Hospital, Middlesbrough, UK ${ }^{5}$ University Hospital Birmingham, Birmingham, UK ${ }^{6}$ Defence Medical Services, Islamabad, Pakistan
\end{abstract}

\section{Correspondence to}

Douglas M Bowley, Department of Surgery, 16 Medical

Regiment, Merville Barracks, Colchester CO2 7UT, UK; doug. bowley@heartofengland.nhs.uk

Received 30 October 2017 Revised 28 June 2018 Accepted 28 June 2018 Published Online First 4 August 2018

\section{Check for updates}

(C) Author(s) (or their employer(s)) 2019. No commercial re-use. See rights and permissions. Published by BMJ.

To cite: Bowley DM, Lamb D, Rumbold P, et al.

J R Army Med Corps

2019:165:143-146.

\section{ABSTRACT}

Introduction The WHO Constitution enshrines '...the highest attainable standard of health as a fundamental right of every human being.' Strengthening delivery of health services confers benefits to individuals, families and communities, and can improve national and regional stability and security. In attempting to build international healthcare capability, UK Defence Medical Services (DMS) assets can contribute to the development of healthcare within overseas nations in a process that is known as Defence Healthcare Engagement (DHE).

Methods In the first bespoke DMS DHE tasking, a team of 12 DMS nurses and doctors deployed to a 1000-bedded urban hospital in a partner nation and worked alongside indigenous healthcare workers (doctors, nurses and paramedical staff) during April and May 2016. The DMS nurses focused on nursing hygiene skills by demonstrations of best practice and DMS care standards, clinical leadership and female empowerment. A Quality Improvement Programme was initiated that centred on hand hygiene (HH) compliance before and after patient contact, and the introduction of peripheral cannula care and surveillance.

Results After a brief induction on the ward, it was apparent that compliance with $\mathrm{HH}$ was poor. Peripheral cannulas were secured with adhesive zinc oxide tape and no active surveillance process (such as venous infusion phlebitis (VIP) scoring) was in place. After intensive education and training, initial week-long audits were undertaken and repeated after a further 2 weeks of training and coworking. In the second audit cycle, HH compliance had increased to $69 \%$ and VIP scoring compliance to $99 \%$. In the final audit cycle, it was noted that nursing compliance with $\mathrm{HH}(75 / 98: 77 \%)$ was significantly higher than the doctors' HH compliance (76/200: 38\%); $p<0.0001$.

Conclusions DHE is a long-term collaborative process based on the establishment and development of comprehensive relationships that can help transform indigenous healthcare services towards patient-centred systems with a focus on safety and quality of care. Short deployments to allow clinical immersion of UK healthcare workers within indigenous teams can have an immediate impact. Coworking is a powerful method of demonstrating standards of care and empowering staff to institute transformative change. A multidisciplinary group of Quality Improvement Champions has been identified and a Hospital Oversight Committee established, which will offer the prospect of longer term sustainability and development.

\section{Key messages}

Defence Medical Services assets can contribute to the development of healthcare within overseas nations in a process that is known as Defence Healthcare Engagement.

- Coworking is a powerful method of demonstrating standards of care and empowering staff to institute transformative change.

- A multidisciplinary group of Quality Improvement Champions has been identified.

- A Hospital Oversight Committee has been established which will offer the prospect of longer term sustainability and development.

- Short deployments to allow clinical immersion of UK healthcare workers within indigenous teams can have an immediate impact.

\section{INTRODUCTION}

The 2010 Strategic Defence and Security Review ${ }^{1}$ and 2015 National Security Strategy (NSS) ${ }^{2}$ outline two strategic aims for the UK. The first was to ensure a 'secure and resilient UK', and the second to help 'shape a stable world'. Short of combat operations, military assets have the capabilities to achieve influence beyond their country of origin. These so-called 'soft power' activities include: defence diplomacy; defence and security exports; conflict prevention, postconflict reconstruction and stabilisation and, collectively, have been called Defence Engagement (DE). UK defence doctrine established in $2015^{3}$ suggests that DE should be 'an approach to relationship building through direct assistance and shared endeavour that creates the right conditions, spirit and capabilities to achieve a formal and enduring partnership.' Healthcare is a universal need and healthcare workers use a common language; they share similar objectives and a compassionate service culture. Projection of UK Defence Medical Services (DMS) nursing and medical capability to work closely with peers enables direct sharing of best practice and indirectly contributes to building strategic relationships and ensuring greater understanding between nations. ${ }^{4}$

Between April and May 2016, a triservice UK delegation comprising four clinical nurses, seven consultants from various specialities and one nurse manager deployed in a Defence Healthcare Engagement (DHE) role to support the Pakistani Armed Forces, termed OPERATION PANAKA. Specialists 
from emergency medicine, anaesthetics and critical care, trauma and orthopaedics, burns and plastics, oral and maxillofacial surgery, general surgery and ophthalmology were represented in the clinical team. Two nurse educators joined the team to implement a bespoke Quality Improvement Programme (QIP) training package. The clinical and educational components of the programme took place at the Combined Military Hospital $(\mathrm{CMH})$ Rawalpindi, which is a 1000-bedded teaching hospital and at the Armed Forces Institute of Ophthalmology in the Rawalpindi cantonment. The aim of this paper is to examine the impact of this first DHE deployment and look to the future for further opportunities.

\section{METHODS}

Focus on nursing hygiene skills

A team of 12 DMS nurses and doctors deployed and worked alongside indigenous healthcare workers (doctors, nurses and paramedical staff). The DMS nurses concentrated their efforts on demonstrations of best practice in nursing hygiene skills and DMS care standards, clinical leadership and female empowerment. The QIP centred on hand hygiene $(\mathrm{HH})$ compliance, according to WHO standards, and the introduction of peripheral cannula care and surveillance. The WHO 'five moments of hand bygiene ${ }^{5}$ is an internationally recognised standard for safe practice and was therefore the framework selected against which to measure compliance. The principles of safe care are underpinned by a reduction in the spread of pathogenic microorganisms ${ }^{6}$; therefore, the focus on $\mathrm{HH}$ would serve two important purposes. It would highlight the importance of infection control by the multidisciplinary team while outlining how a simple, achievable process could be audited quickly and have significant impact on patient outcomes. This would improve the patient experience and have significant cost saving implications that could then be invested in further development of the healthcare system. The WHO has estimated that, in a typical hospital, excess costs associated with only four or five healthcare-associated infections (HCAI) of average severity may equal the entire annual budget for $\mathrm{HH}$ products used in inpatient care areas. An economic analysis of the 'clean your hands' $\mathrm{HH}$ promotional campaign conducted in England and Wales concluded that the programme would be cost beneficial if HCAI rates were decreased by as little as $0.1 \%{ }^{6}$

\section{Sharing learning}

The academic component of the project took the shape of nursing modules, multidisciplinary teaching using workshops and workplace-based interaction and case discussion. The intent of the bespoke teaching package was to provide dynamic learning opportunities for student and graduate nurses at the CMH Rawalpindi. This transcultural approach accepted that a UK healthcare model would not directly translate to the host nation. Therefore, by facilitating emic (from the perspective of the subject) and etic (from the perspective of the observer) comparisons to the delivery of safe care, an exciting and highly creative learning environment was promoted, ${ }^{7}$ which provided the foundations to broaden the scope of nursing care at the bedside. This learning programme aimed to empower nurses to focus on the quality of the care they were delivering. Quality improvement initiatives had not previously been regarded as a nurse's direct responsibility, so audit was a new concept. The initial plan had been to teach 20 nurses, who would work with the DMS nursing team after training, to apply their newly acquired skills. However, such was the enthusiasm to receive training that these figures

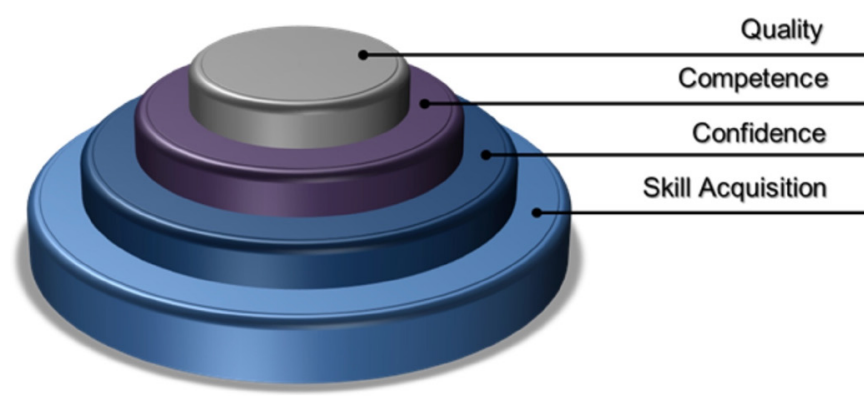

Figure 1 Defence Engagement nurse education model (Copyright $($ ) Professor D Lamb).

swelled significantly with almost 300 training places made available during an intensive 1 -week programme. Consequently, while some achieved the initial intent of practising directly with the DMS nursing team, the remainder returned to their hospitals all over the country to implement their new skills and broaden the reach of this initial stage of training.

The principles of audit were underlined in the classroom and then practised in the clinical environment under the supervision of the UK team. This demonstrated the physical bridge between theory and practice; as previously, practical skills had predominantly been taught and validated only in a simulated environment. True empowerment for nurses to engage in activity that would make a difference to care standards needed to be rooted in its realistic context; otherwise it would be unlikely that a positive culture of quality improvement would evolve. The premise of this educational model is illustrated in Figure 1 and was fully supported by doctors who were champions of this nurse-led initiative with a shared passion to promote quality improvement in the clinical area. Organisational champions have proved highly effective in instrumenting reform across health systems ${ }^{8}$ and would assist nurses to have their voices heard.

\section{RESULTS}

On arrival at the ward, it was apparent that compliance with $\mathrm{HH}$ was poor. Peripheral cannulas were secured with adhesive zinc oxide tape and no active surveillance process for peripheral cannulas (such as venous infusion phlebitis (VIP) scoring) was in place. After intensive education and training, initial week-long audits were undertaken. These were repeated after a further 2 weeks of training and coworking. In this second audit cycle, $\mathrm{HH}$ compliance overall had increased to $69 \%$ and VIP scoring compliance was 99\% (Table 1).

\begin{tabular}{|c|c|c|c|c|}
\hline & Baseline & Week 1 & Week 3 & $P$ values \\
\hline $\begin{array}{l}\text { Hand hygiene } \\
\text { compliance } \\
\text { (all practitioners) }\end{array}$ & Near zero & $\begin{array}{l}89 / 170 \\
(52 \%)\end{array}$ & $243 / 352(69 \%)$ & 0.0003 \\
\hline $\begin{array}{l}\text { Hand hygiene } \\
\text { compliance } \\
\text { (doctors vs nurses) }\end{array}$ & & & $\begin{array}{l}\text { Doctors: 76/200 (38\%) } \\
\text { Nurses: } 75 / 98(76.5 \%)\end{array}$ & $<0.0001$ \\
\hline $\begin{array}{l}\text { Clear dressings for } \\
\text { peripheral cannulas }\end{array}$ & Nil & $\begin{array}{l}54 / 126 \\
(43 \%)\end{array}$ & $85 / 90(94 \%)$ & 0.0001 \\
\hline VIP score compliance & Nil & $\begin{array}{l}83 / 126 \\
(66 \%)\end{array}$ & $89 / 90(99 \%)$ & 0.0001 \\
\hline
\end{tabular}

CMH, Combined Military Hospital; VIP, venous infusion phlebitis. 


\section{Feedback from nursing learning}

Each quality improvement training course comprised 2 days of initial classroom-based education that introduced both military and civilian nurses to the definition of quality, how it might be measured within this cultural context and their role in the management of change. The ensuing discussions highlighted nurses' perceived organisational constraints that were then raised in consultation with the senior hospital executive to identify ways in which these might be mitigated. In so doing, the seeds of nurse (female) empowerment within the organisation were being sewn. It was evident that nurses' baseline theoretical knowledge was sound as the training material resonated with their own curriculum; but an understanding of its application was not so confidently demonstrated. Therefore, the UK clinical team, who had also received the same training as the indigenous nurses, were able to fully understand the approach required to engage their enthusiasm in applying new skills and broadening their scope of practice. The statistically significant improvements in $\mathrm{HH}$, clear dressing application and the documentation of VIP scores demonstrate a clear understanding of the application of quality improvement principles. Compliance with $\mathrm{HH}$ among nurses $(76.5 \%)$ was found to be significantly better than doctors (38\%) in the second audit cycle. It was only nurses who received the educational input in the initial classroom-based training suggesting that theory and practical re-enforcement in the clinical environment go hand in hand to promote positive behavioural change.

Part of the programme was a session on identifying potential quality improvement projects that could be undertaken once the initial 6-week UK training phase was completed. The aim was to ensure that the behavioural change was enduring. There was a risk that, without the presence of the UK delegation and constant support to ensure compliance with these new standards was being measured, behaviour would revert back to type and progress would stall. Therefore, indigenous nurses were provided with the means of becoming innovative in their thinking and courageous in their actions, which were the attributes of a nurse leader they would require to help shift a culture that had stymied such endeavour to date.

\section{DISCUSSION}

The WHO Constitution enshrines '...the highest attainable standard of health as a fundamental right of every human being. ${ }^{9}$ In addition to this basic human right, Article 25 of the United Nations (UN) Charter of Human Rights asserts that being healthy and having access to healthcare are essential elements of human security. ${ }^{10}$ Strengthening delivery of health services confers benefits to individuals, families and communities, and can improve national and loco-regional stability and security. At an international level therefore, healthcare and security can be seen as mutually dependent and the UK now recognises the importance of $\mathrm{DE}$ in preventing conflict, building stability and gaining influence, to the point where DE is now a funded core MOD task.

As part of the NSS, ${ }^{2}$ seven DE objectives have been suggested: to defend; protect; influence; promote; understand; build; and deter. In order to achieve these goals, four DE strategic aims have been elaborated:

1. Establish comprehensive relationships and an understanding of the global and regional context, through persistent and modulated engagement in support of our standing commitments, and support to intelligence and diplomatic priorities.
2. Build international capability, capacity and will by strengthening existing alliances and developing partnerships with non-traditional partners that support and enhance UK security and economic relationships through defence diplomacy. Acting early to prevent conflict and tackle the root causes of instability, including helping to build partner capacity and contributing to peacekeeping operations.

3. Sustain our position and influence with, and through, our allies, partners and multilateral organisations, including our UN Security Council membership.

4. Protecting and promoting our prosperity and security by assuring UK access to secure and affordable resources, and protecting and promoting a stable, rules-based international system that supports our national security and prosperity interests.

DE requires strategy and deliberate planning, characterised by a long-term, collaborative approach with partner nations; conducted in a manner that is integrated with other government departments, particularly Foreign and Commonwealth Office and the Department for International Development.

The UK has a global network of alliances and partnerships, often underpinned by common language and long-standing historical affiliations. Healthcare is a universal need and healthcare engagement appears to be a welcomed and non-contentious intervention. Successful DE activities depend on credibility and, in 2017, the NHS was judged the best, safest and most affordable healthcare system out of 11 countries analysed and ranked by experts from the influential Commonwealth Fund health think tank. ${ }^{11}$ The UK DMS have also been independently rated as performing to a very high standard. In 2009, following a sustained period of intense combat support activity, the deployed UK DMS were evaluated by an independent body of healthcare experts who visited the deployed UK combat support hospital in Afghanistan. Their assessment was that trauma management by the DMS was 'exemplary' and the President of the Royal College of Surgeons, Mr John Black, was quoted as stating: 'the results achieved in the management of the injured soldier in the current conflicts are the best ever reported... this is a truly remarkable achievement. ${ }^{12}$

Deployed DMS service personnel have often used DHE techniques, whether in a primarily combat support roles or on humanitarian and disaster relief operations, to directly deliver care to indigenous people or to help with security sector reform and development of the civilian health sector. ${ }^{13-15}$ However, stand-alone DHE is now enshrined as a core UK Defence task with its own Centre for DHE. ${ }^{16}$ By drawing on NHS and DMS collective experience, we can share best practice and collaborate in development of impactful Quality Improvement Projects by undertaking practical and value-adding audit and governance. In developing healthcare projects with selected partners and achieving small but measureable success such as that described in this report, the UK's DMS can contribute to the building of host nation capability. This must be carried out while fostering a no-blame culture and striving for greater female empowerment. DHE must adhere to UK doctrine concerning the medical contribution to security and stability overseas; DHE must: do no harm; be clinically appropriate; culturally sensitive; coherent; sustainable; coordinated and retain civilian primacy. ${ }^{17}$

DMS staff undertaking DHE must strive to empower indigenous coworkers to transform their healthcare processes aiming for quality in healthcare (defined as a fusion of three aspects: safety, clinical effectiveness and patient experience ${ }^{18}$ ). As well as providing the means of transformation within the host nation's medical system, DHE is an opportunity to improve bilateral 
interoperability. As UK Defence again takes an increasing part in UN operations in conducting peacekeeping, humanitarian assistance and disaster relief or military assistance to the civil authorities, the UK will be working alongside other nations under the blue beret. Prior DE activities enabling interoperability will greatly facilitate delivery of UN missions with a variety of partner organisations and nations.

DHE does not need to be complicated or focus on costly medical technology or capability; the Centers for Disease Control and Prevention states that 'clean hands are the single most important factor in preventing the spread of pathogens and antibiotic resistance in healthcare settings. ${ }^{19}$ Barriers to compliance with $\mathrm{HH}$ include low prioritisation, insufficient time, inconvenience of hand wash equipment placement, allergy or intolerance of antiseptics and lack of leadership, whether role models or senior management. ${ }^{20}$ In addition, as this study confirmed, compliance with $\mathrm{HH}$ practices appears to be inversely associated with status, with doctors less likely to wash their hands compared with nurses. ${ }^{21}$ In the face of compelling evidence, doctors' tendency to resist change because it contradicts established norms or entrenched behaviour has been called the Semmelweis reflex, named after the 19th century physician whose life ended in an asylum, where he had been driven by the rejection by his peers of his ideas around $\mathrm{HH}^{22}$ We recognise a potential limitation to the results found. Notwithstanding the measurement of significant improvements in compliance with $\mathrm{HH}$ and VIP scoring, and so on, a Hawthorne effect cannot be discounted. The Hawthorne effect (also referred to as the observer effect) is a type of human behaviour in which individuals modify an aspect of their behaviour in response to their awareness of being observed. ${ }^{23}$ A UK presence in the clinical area during these audits and the heightened hospital-wide focus to support the visiting delegation are likely to have influenced the behaviour of healthcare practitioners in the shorter term. It will only be possible to measure true cultural change over the longer term so this will be re-evaluated at the next stage of the training programme.

Finally, DHE is not easy or without possible unintended consequences; indeed only recently, UK Doctrine suggested that "Where possible, the international military role in the (indigenous) civilian health sector is to "do nothing.".17 However, the world faces common threats and progress will only come with greater understanding and collaboration between nations. Medicine is a 'universal language' and the UK now leads the world in striving to achieve quality in healthcare. DHE is a long-term collaborative process based on the establishment and development of comprehensive relationships that can help transform indigenous healthcare services towards patient-centred systems with a focus on safety and quality of care. Short deployments to allow clinical immersion of UK healthcare workers within indigenous teams can have an immediate impact. Coworking is a powerful method of demonstrating standards of care and empowering staff to institute change. The identification and promotion of Quality Improvement Champions offers the prospect of longer term sustainability and development.

Contributors Planning: DMB, MB. Conducting: DMB, DL, PR, PH, JK, AMS, MB. Reporting: DMB, DL, PR, PH, JK, AMS, MB.
Funding The authors have not declared a specific grant for this research from any funding agency in the public, commercial or not-for-profit sectors.

Competing interests None declared.

Patient consent Not required.

Provenance and peer review Commissioned; internally peer reviewed.

\section{REFERENCES}

1 Strategic Defence and Security Review (SDSR). 2010. https://www.gov.uk/ government/uploads/system/uploads/attachment_data/file/62482/strategic-defencesecurity-review.pdf (accessed 01 Oct 2017).

2 National Security Strategy and Strategic Defence and Security Review 2015: A Secure and Prosperous United Kingdom. https://www.gov.uk/government/uploads/system/ uploads/attachment_data/file/478933/52309_Cm_9161_NSS_SD_Review_web_ only.pdf (accessed 01 Oct 2017).

3 Joint Doctrine Note 1/15. Defence Engagement. https://www.gov.uk/government/ uploads/system/uploads/attachment data/file/570579/20160104-Defence engagement_jdn_1_15.pdf (accessed 01 Oct 2017).

4 Whitaker J, Bowley D. Beyond bombs and bayonets: Defence Engagement and the Defence Medical Services. J R Army Med Corps 2019;165:140-2.

5 World Health Organization. A manual for WHO "My five moments of hand hygiene" concept. Geneva: World Health Organization, 2008.

6 World Health Organization. WHO guidelines on hand hygiene in health care: First global patient safety challenge clean care is safe care. Geneva: World Health Organization, 2009. (accessed 01 Oct 2017).

7 Leininger $M$. Teaching transcultural nursing in undergraduate and graduate programs. J Transcult Nurs 1995;6:10-26.

8 Hendy J, Barlow J. The role of the organizational champion in achieving health system change. Soc Sci Med 2012;74:348-55.

9 World Health Organization. The World Health Organization Constitution. 2005. http:// apps.who.int/gb/bd/PDF/bd47/EN/constitution-en.pdf?ua=1 (accessed 01 Oct 2017).

10 United Nations. The universal declaration of human rights. General Assembly resolution $217 \mathrm{~A}$ (III) of 10 December 1948 http://www.un.org/Overview/rights.html (accessed 01 Oct 2017)

11 Schneider EC, Sarnak DO, Squires D, et al. Mirror, Mirror 2017: International Comparison Reflects Flaws and Opportunities for Better U.S. Health Care. 2017. http://www.commonwealthfund.org/interactives/2017/july/mirror-mirror/ (accessed 01 Oct 2017)

12 Commission for Healthcare Audit and Inspection. Defence medical services - a review of the clinical governance of the Defence Medical Services in the UK and overseas. 2009. http://www.nhs.uk/Defencemedicine/Documents/Defence_Medical_Services review\%5B1\%5D.pdf (accessed 01 Oct 2017).

13 Bricknell MC, Gadd RD. Roles for international military medical services in stability operations (reconstruction and development). J R Army Med Corps 2007;153:160-4.

14 Bricknell MC, Thompson D. Roles for international military medical services in stability operations (security sector reform). J R Army Med Corps 2007;153:95-8.

15 Bricknell MC, MacCormack T. ABC of conflict and disaster: military approach to medical planning in humanitarian operations. BMJ 2005;330:1437-9.

16 Bricknell M, Sullivan R. The centre for defence healthcare engagement: a focus for defence engagement by the defence medical services. J R Army Med Corps 2018;164:5-7

17 Joint Doctrine Note 3/14 (JDN 3/14). The military medical contribution to security \& stabilisation. https://www.gov.uk/government/uploads/system/uploads/attachment data/file/324637/20140616-JDN 3 14_Med contr_DCDC.pdf (accessed 01 Oct 2017).

18 Berwick D. A promise to learn - a commitment to act. London: Department of Health, 2013.

19 Center for Disease Control Atlanta. Hand hygiene. https://www.cdc.gov/handhygiene/ download/hand_hygiene_core.pdf (accessed 01 Oct 2017).

20 Boyce JM. It is time for action: improving hand hygiene in hospitals. Ann Intern Med 1999;130:153-5.

21 Eckmanns T, Schwab F, Bessert J, et al. Hand rub consumption and hand hygiene compliance are not indicators of pathogen transmission in intensive care units. J Hosp Infect 2006;63:406-11.

22 York EP, Brown T. The price they paid. J Community Hosp Intern Med Perspect 2015;5:26436.

23 McCambridge J, Witton J, Elbourne DR. Systematic review of the Hawthorne effect: new concepts are needed to study research participation effects. J Clin Epidemiol 2014;67:267-77 